\title{
Quantitative Electroencephalography Reflects Inattention, Visual Error Responses, and Reaction Times in Male Patients with Attention Deficit Hyperactivity Disorder
}

\author{
Sang-Choong Roh ${ }^{1}$, Eun-Jin Park², Young-Chun Park ${ }^{1,3}$, Sun-Kyung Yoon ${ }^{1,4}$, Joong-Gu Kang ${ }^{1}$, Do-won Kim ${ }^{1,5}$, \\ Seung-Hwan Lee ${ }^{1,2^{3}}$ \\ ${ }^{1}$ Clinical Emotion and Cognition Research Laboratory, Inje University, Seoul, ${ }^{2}$ Department of Psychiatry, Inje University IIsan Paik Hospital, \\ Goyang, ${ }^{3}$ Department of Psychiatry, Korea University, ${ }^{4}$ Department of Psychiatry, Sogang University, ${ }^{5}$ Department of Biomedical \\ Engineering, Hanyang University, Seoul, Korea
}

\begin{abstract}
Objective: Quantitative electroencephalography (qEEG) has been increasingly used to evaluate patients with attention deficit hyperactivity disorder (ADHD). The aim of this study was to assess the correlation between qEEG data and symptom severity in patients with $A D H D$.

Methods: Fifteen patients with ADHD and 20 healthy controls (HCs) were recruited. Electroencephalography was assessed in the resting-state, and qEEG data were obtained in the eyes-closed state. The Korean version of the ADHD Rating Scale (K-ARS) and continuous performance tests (CPTs) were used to assess all participants.

Results: Theta-band $(4-7 \mathrm{~Hz})$ power across the brain was significantly positively correlated with inattention scores on the K-ARS, reaction times and commission errors on the CPTs in ADHD patients. Gamma-band $(31-50 \mathrm{~Hz})$ power was significantly positively correlated with the results of the auditory CPTs in ADHD patients. The theta/alpha $(8-12 \mathrm{~Hz})$ and theta/beta $(13-30 \mathrm{~Hz})$ ratios were significantly negatively correlated with commission and omission errors on auditory CPTs in ADHD patients. No significant correlations between GEEG relative power and K-ARS and CPT scores were observed in HCs.

Conclusion: Our results suggest that qEEG may be a useful adjunctive tool in patients with ADHD.
\end{abstract}

KEY WORDS: Attention deficit disorder with hyperactivity; Continuous performance tests; Inattention; Quantitative electroencephalography; Theta.

\section{INTRODUCTION}

Attention deficit hyperactivity disorder (ADHD) is one of the most common disorders treated by child and adolescent psychiatrists in America, affecting as many as $50 \%$ of patients admitted to child psychiatry clinics. ${ }^{1)}$ The Diagnostic and Statistical Manual of Mental Disorders fourth edition (DSM-IV) $)^{2}$ estimated the prevalence of ADHD in school-age children as approximately 3-5\%, and the prevalence of ADHD in Korea ranges from $4 \%$ to $5 \%$ among children. ${ }^{3)}$ According to the DSM-IV, patients with ADHD are characterized by developmentally inappropriate degrees of inattention, impulsivity, and hyper-

\footnotetext{
Received: October 27, 2014 / Revised: January 28, 2015

Accepted: March 2, 2015

Address for correspondence: Seung-Hwan Lee, MD, PhD Department of Psychiatry, Inje University IIsan Paik Hospital, 170 Juhwa-ro, Ilsanseo-gu, Goyang 10380, Korea

Tel: +82-31-910-7260, Fax: +82-31-910-7268

E-mail: Ishpss@paik.ac.kr
}

activity in more than one environment. ${ }^{2)}$

Continuous performance tests (CPTs) have attracted increased attention as tools to assess the cognitive mechanisms associated with neuropsychiatric disorders, particularly ADHD. The ability to maintain an attention span is crucial for success in daily living and in learning essential academic skills in the classroom. ${ }^{4)}$ Children with ADHD have difficulty sustaining the attention required for completing demanding tasks, are inattentive to environmental cues, and suffer from concurrent impairments across multiple settings, including those involving academic tasks and peer relationships. Thus, identification of the mechanisms responsible for regulating and maintaining sustained attention and effort have been key components of theories attempting to elucidate the etiology of ADHD. ${ }^{5)}$

Electroencephalographic (EEG) studies provide useful information about the brain function of ADHD patients. The resting-state EEG is a useful source of information regarding background brain functions, indicating the sub-

(a) This is an Open-Access article distributed under the terms of the Creative Commons Attribution Non-Commercial License (http://creativecommons.org/licenses/by-nc/4.0) which permits unrestricted non-commercial use, distribution, and reproduction in any medium, provided the original work is properly cited. 
strates of cognition and behavior. Barry et al. ${ }^{6)}$ reported that elevated relative theta power, reduced relative alpha and beta power, and elevated theta/alpha and theta/beta ratios in resting-state EEGs were the most common findings associated with ADHD. Chabot and Serfontein ${ }^{7)}$ revealed EEG differences between 407 children diagnosed with ADHD according to The Diagnostic and Statistical Manual of Mental Disorders third edition (DSM-III) criteria. Children with ADHD showed increased absolute and relative theta power in the frontal brain regions, and patients with ADHD exhibited cortical EEG slowing during the performance of different tasks and under different conditions. This was reflected in a significant increase in the activity in the lower frequencies of human EEGs, primarily in the theta range, and reductions in the amplitudes in the beta range. ${ }^{7-10)}$

Most previous EEG studies of ADHD have focused on band power, ratio coefficients, and consistency between patients and healthy controls (HCs). Few studies have reported on relationships between qEEG and CPTs. Song et $a l .{ }^{11)}$ found that methylphenidate induced a significant increase in alpha and beta activities and a reduction in theta activities and in the theta/beta ratio in certain brain areas during CPTs. However, no significant qEEG changes were induced by administration of methylphenidate in the resting state. Well-structured studies elucidating the relationship between neurocognitive functions and qEEG are therefore lacking.

Our study was designed to examine the relationship between cognitive performance tests and qEEG during the resting state, which is the most important measure in ADHD studies. ${ }^{6}$ We hypothesized that: (1) the symptom severity of ADHD patients will be positively related to theta-wave activities, and (2) qEEG data will be significantly correlated with the results of CPTs in patients with ADHD.

\section{METHODS}

\section{Subjects}

Fifteen patients with $\mathrm{ADHD}$ (mean age $=9.8 \pm 1.61$ years) and $20 \mathrm{HCs}$ (mean age $=9.4 \pm 0.88$ years) were recruited from Department of Psychiatry, Inje University Ilsan Paik Hospital. All patients were diagnosed following a semistructured clinical interview conducted by child and adolescent psychiatrists using the Korean-Schedule for Affective Disorders and Schizophrenia for School-age Children (K-SADS), and those who met DSM-IV text revision criteria for ADHD were invited to participate in this study. All patients with ADHD had been drug-naïve for at least 2 weeks. Exclusion criteria included the presence of any of the following: an identifiable neurological disorder, a head injury, mental retardation, an identifiable psychiatric disorder other than ADHD, and a physical illness that could affect cognitive function or cause hearing loss. We obtained written informed consent from all participants as well as from the next of kin, caretakers, or guardians of all minors/children enrolled in our study before any study-related tests were performed. The study protocol was reviewed and approved by the institutional review board of Inje University Ilsan Paik Hospital (IRB number: IB-1101-008).

The $20 \mathrm{HC}$ subjects were recruited from the community around the hospital. They were examined with the Structured Clinical Interview for DSM fourth edition (SCID) to screen out those with a personal history of psychiatric or neurological abnormalities. Reliable informants were also interviewed to acquire additional information regarding the cognitive and functional capacity and medical history of the subjects. Only males were included in this study because of the predominance of males among hyperactive children. ${ }^{12)}$

The demographic data for the study and control groups are summarized in Table 1; no significant differences in age and gender were observed between the two groups.

\section{Neuropsychological Measurements}

All ADHD subjects and their next of kin/parents/guardians completed a comprehensive and standardized battery of psychological tests, including the Korean Educational Development Institute's Wechsler Intelligence Scales for Children (KEDI-WISC-II) and the Korean version of the ADHD Rating Scale (K-ARS) parent form, respectively. The KEDI-WISC-II tests vocabulary, arithmetic, picture arrangement, and block design, ${ }^{13)}$ whereas the ARS is a behavior-rating scale consisting of 18 items, 9 of which address inattention and 9 of which address hyperactivity/ impulsivity. K-ARS for parents and teachers are highly valid and reliable. $^{14)}$

A computerized $\mathrm{CPT}^{15)}$ was used to measure inattention, impulsivity, and sustained attention deficits in children with ADHD. The ADHD Diagnostic System (ADS), which was used as a CPT, is a standardized diagnostic system, and its validity and reliability have been well established in Korean patients with ADHD. ${ }^{16)}$ This instrument consists of auditory and visual tests focused on three major variables: (1) omission errors (inattention), (2) commission errors (impulsivity), and (3) reaction times 
Table 1. Descriptive statistics from the demographic and neuropsychological tests of K-ARS, IQ test, and relative power of ADHD patients and healthy controls

\begin{tabular}{|c|c|c|c|c|c|}
\hline Variable & $\operatorname{ADHD}(n=15)$ & Healthy controls $(n=20)$ & $t\left(x^{2}\right)$ & $d f$ & $p$ value \\
\hline Sex (male : female) & $15: 0$ & $20: 0$ & & & NS \\
\hline Age $(y r)$ & $9.80(1.61)$ & $9.40(0.88)$ & 0.93 & 33 & NS \\
\hline K-ARS (total) & $27.20(9.05)$ & $9.70(7.02)$ & 6.44 & 33 & $0.000^{\star \star \star}$ \\
\hline Inattention & $14.67(3.75)$ & 5.25 (3.89) & 7.19 & 33 & $0.000^{* * *}$ \\
\hline Hyperactivity & $12.53(5.95)$ & $4.45(3.33)$ & 5.11 & 33 & $0.000^{* * *}$ \\
\hline IQ (total score) KEDI-WISC-II & $110.30(13.30)$ & $114.05(17.32)$ & -0.60 & 33 & NS \\
\hline Global full band $(1-50 \mathrm{~Hz})$ & $1.80(0.61)$ & $2.80(1.35)$ & -2.66 & 33 & $0.012^{*}$ \\
\hline Gamma (31-50 Hz) & $0.012(0.003)$ & $0.016(0.006)$ & -1.93 & 33 & 0.082 \\
\hline Beta $(13-30 \mathrm{~Hz})$ & $0.069(0.022)$ & $0.070(0.014)$ & -0.05 & 33 & 0.955 \\
\hline Alpha (8-12 Hz) & $0.322(0.095)$ & $0.341(0.089)$ & -0.61 & 33 & 0.547 \\
\hline Theta $(4-7 \mathrm{~Hz})$ & $0.161(0.610)$ & $0.155(0.035)$ & 0.35 & 33 & 0.728 \\
\hline Delta $(1-3 \mathrm{~Hz})$ & $0.369(0.074)$ & $0.357(0.072)$ & 0.47 & 33 & 0.640 \\
\hline
\end{tabular}

Values are presented as mean (standard deviation).

NS, not significant; ADHD, attention deficit hyperactivity disorder; K-ARS, Korean vesion of ADHD Rating Scale; $1 Q$, intelligence quotient; df, degree of freedom; KEDI-WISC-II, Korean Educational Development Institute's Wechsler Intelligence Scales for Children. ${ }^{*} p<0.05,{ }^{* * *} p<0.001$.

(information processing and motor reaction speed).

\section{EEG Recording and QEEG Analysis}

The subjects were seated in a dimly lit and sound-attenuated room. Subjects were positioned approximately $100 \mathrm{~cm}$ from a 17-inch CRT-monitor. The resting-state EEG was recorded with subjects' eyes open and eyes closed for 3 minutes each. EEG signals were recorded using a NeuroScan SynAmps 2 amplifier (Compumedics, El Paso, TX, USA) from 62 surface electrodes (FP1, FPZ, FP2, AF3, AF4, F7, F5, F3, F1, FZ, F2, F4, F6, F8, FT7, FC5, FC3, FC1, FCZ, FC2, FC4, FC6, FT8, T7, C5, C3, C1, CZ, C2, C4, C6, T8, TP7, CP5, CP3, CP1, CPZ, CP2, CP4, CP6, TP8, P7, P5, P3, P1, PZ, P2, P4, P6, P8, PO7, $\mathrm{PO} 5, \mathrm{PO} 3, \mathrm{POZ}, \mathrm{PO} 4, \mathrm{PO} 6, \mathrm{PO} 8, \mathrm{CB} 1, \mathrm{O} 1, \mathrm{OZ}, \mathrm{O} 2$, and CB2) mounted on a Quik-Cap (Compumedics) according to the extended international 10-20 placement scheme. The ground electrode was placed on the forehead, and the reference electrodes were located at the $\mathrm{CZ}$ electrode. The vertical electro-oculogram (EOG) was recorded using bipolar electrodes; one was located above and one was located below the right eye. A horizontal EOG was recorded at the outer canthus of each eye. The impedance of the electrodes was maintained at less than $5 \mathrm{k} \Omega$.

EEG data were recorded with a $0.1-100 \mathrm{~Hz}$ band-pass filter at a sampling rate of $1,000 \mathrm{~Hz}$. EEG data were initially processed using Scan 4.3. Eye movements were visually screened and eliminated by one expert EEG operator. In this study, we analyzed the resting EEG data with eyes closed. EEG data were initially referenced to an average reference and divided into epochs with a length of $\sim 2 \mathrm{~s}$ (2,048 points). Epochs with signals exceeding \pm 150 $\mu \mathrm{V}$ on any channel were eliminated from the analysis. A total of 30 epochs $(\sim 60 \mathrm{~s})$ were prepared for each subject.

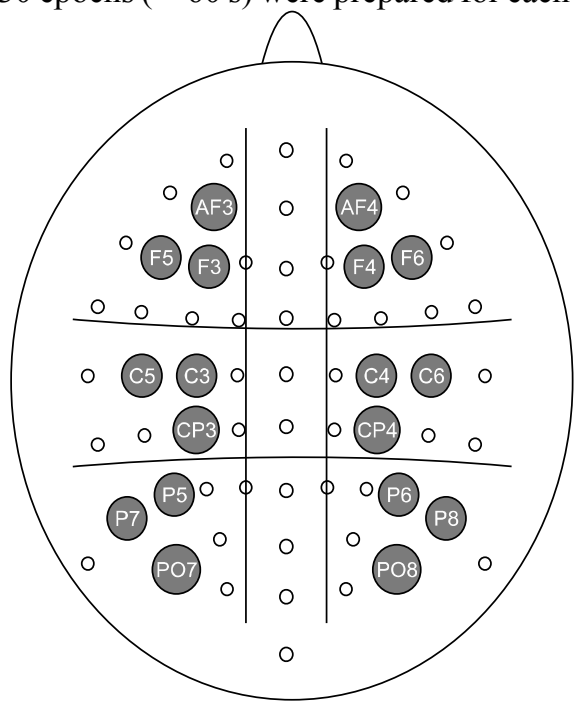

Fig. 1. The 62 recording sites and demarcation of the six regions.

Fast Fourier transformation was performed on 62 electrode channels divided into five frequency bands: delta (1-3 Hz), theta (4-7 Hz), alpha (8-12 Hz), beta (13-30 Hz), and gamma $(31-50 \mathrm{~Hz})$. Then, the relative power of each channel was calculated by dividing each band power by the total power of the channel. The relative power of three electrodes was averaged into six regions. Six regions were selected for further analysis (Fig. 1): left frontal (AF3, F3, and F5), right frontal (AF4, F4, and F6), left central (C3, $\mathrm{C} 5$, and $\mathrm{CP} 3)$, right central (C4, C6, and $\mathrm{CP} 4)$, left parieto-occipital (P5, P7, and PO7), and right parieto-occipital (P6, P8, and PO8). The division and selection of these regions were based on a previous qEEG study. ${ }^{17)}$ The relative global band powers were calculated over 62 electrode 
channels and then averaged. ${ }^{18,19)}$ We used the relative power in the present study because its effects have been more stable in terms of relative power than in terms of absolute power according to a previous ADHD study. ${ }^{20)}$

\section{Statistical Analysis}

Chi-square $\left(\chi^{2}\right)$ tests were used for the analysis of categorical variables. Independent-sample $t$-tests were used to compare the demographic and clinical data of the two groups. Spearman's correlation analysis was performed to evaluate the relationship between qEEG and ADS test scores in ADHD patients. The bootstrap resampling technique $(\mathrm{n}=5,000)$ was used to correct multiple correlations. The significance level was set at $p<0.05$. Statistical analyses were performed using PASW Statistics software (version 18.0; IBM Co., Armonk, NY, USA).

\section{RESULTS}

The ADHD group consisted of 15 subjects (mean age $=9.8 \pm 1.61$ years, all male), and the HC group consisted of 20 subjects (mean age $=9.4 \pm 0.88$ years, all male). No significant differences in the demographic characteristics and KEDI-WISC-II intelligence quotient (IQ) scores were observed between the two groups. However, we found significant differences between the two groups' $\mathrm{K}$-ARS scores, as the ADHD group scored higher with regard to both inattention (14.67 [3.75] vs. 5.25 [3.89], $t=7.19$, degree of freedom $[d f]=33, p<0.001)$ and hyperactivity (12.53 [5.95] vs. 4.45 [3.33], $t=5.11, d f=33, p$ $<0.001)$ than did the HCs. The qEEG comparison revealed higher overall brain activation in the HC compared with the ADHD group (2.80 [1.35] vs. 1.80 [0.61], $t=2.66$, $d f=33, p<0.012$ ). However, no inter-group differences in gamma, beta, alpha, theta, and delta frequencies were observed. We believe that this was a result of not subcategorizing subjects according to inattentiveness, overactivity, and impulsiveness due to the small sample. Demographic information, neuropsychological test scores, and qEEG data for the ADHD and HC groups are presented in Table 1.

\section{Correlations between qEEG Data and \\ Neuropsychological Scores}

Table 2 shows the correlational patterns between qEEG relative power and K-ARS and CPT scores in ADHD patients. Significant correlations were found in the power of the theta band in patients with ADHD. The theta power in ADHD patients was positively correlated with their inattention scores on the K-ARS. This significant correla-

Table 2. Spearman's correlation (rho) with bootstrapping (5,000 times) between qEEG power and K-ARS and ADS sub scales in six cortical regions in ADHD patients mainly in the inattention and combined category according to K-ARS standard ( $n=15$ )

\begin{tabular}{|c|c|c|c|c|c|c|c|c|c|}
\hline & \multicolumn{3}{|c|}{ K-ARS } & \multicolumn{6}{|c|}{ ADS } \\
\hline & \multirow{2}{*}{ Total } & \multirow{2}{*}{ Inattention } & \multirow{2}{*}{$\begin{array}{l}\text { Hyperactivity } \\
\text { /impulse }\end{array}$} & \multicolumn{2}{|c|}{ Omission error } & \multicolumn{2}{|c|}{ Commission error } & \multicolumn{2}{|c|}{ Reaction time } \\
\hline & & & & Visual & Auditory & Visual & Auditory & Visual & Auditory \\
\hline \multicolumn{10}{|l|}{ Global } \\
\hline Theta & 0.242 & 0.512 & 0.052 & 0.380 & -0.478 & 0.410 & -0.169 & $0.679^{*}$ & -0.387 \\
\hline T/B ratio & 0.231 & 0.260 & 0.193 & -0.130 & $-0.733^{\star \star}$ & 0.237 & -0.507 & 0.196 & -0.200 \\
\hline \multicolumn{10}{|l|}{ Frontal left } \\
\hline Theta & 0.397 & $0.604^{*}$ & 0.231 & 0.120 & -0.565 & 0.246 & -0.507 & 0.642 & -0.059 \\
\hline $\mathrm{T} / \mathrm{A}$ ratio & 0.150 & 0.235 & 0.059 & 0.028 & $-0.629^{\star}$ & -0.064 & -0.493 & 0.637 & -0.314 \\
\hline \multicolumn{10}{|l|}{ Frontal right } \\
\hline Theta & 0.424 & $0.608^{*}$ & 0.252 & 0.083 & -0.619 & 0.182 & -0.352 & 0.619 & -0.292 \\
\hline \multicolumn{10}{|l|}{ Central left } \\
\hline Theta & 0.371 & $0.799^{* *}$ & 0.157 & 0.509 & -0.310 & 0.255 & -0.155 & $0.729^{*}$ & -0.132 \\
\hline \multicolumn{10}{|c|}{ Central right } \\
\hline Theta & 0.319 & 0.524 & 0.097 & 0.611 & -0.118 & 0.232 & -0.068 & $0.729^{*}$ & -0.050 \\
\hline Gamma & 0.140 & -0.286 & 0.245 & 0.380 & 0.351 & 0.228 & $0.781^{* *}$ & -0.333 & -0.219 \\
\hline $\mathrm{T} / \mathrm{A}$ ratio & 0.426 & $0.543^{*}$ & 0.233 & 0.519 & -0.301 & 0.214 & -0.041 & 0.533 & -0.196 \\
\hline \multicolumn{10}{|c|}{ Occipital left } \\
\hline Theta & 0.149 & 0.391 & -0.005 & $0.639^{*}$ & -0.387 & $0.638^{*}$ & -0.059 & 0.273 & -0.314 \\
\hline \multicolumn{10}{|c|}{ Occipital right } \\
\hline Theta & 0.030 & 0.268 & -0.061 & 0.176 & -0.601 & 0.501 & $-0.708^{*}$ & 0.196 & 0.082 \\
\hline T/B ratio & 0.145 & 0.206 & 0.148 & -0.333 & -0.633 & 0.241 & $-0.740^{\star *}$ & 0.000 & 0.228 \\
\hline
\end{tabular}

Significant differences are indicated with asterisks.

ADHD, attention deficit hyperactivity disorder; qEEG, quantitative electroencephalography; K-ARS, Korean version of ADHD Rating Scale; ADS, ADHD Diagnostic System analyzing omission and commission errors on both visual and auditory test; T/B, Theta/Beta; T/A, Theta/Alpha. ${ }^{*} p<0.05,{ }^{* *} p<0.01$. 
tion was found in the left frontal $(r=0.604, p=0.015)$, the right frontal $(r=0.608, p=0.022)$, and the left central $(r=0.799, p=0.003)$ regions. The theta/alpha ratio reflected a significant positive correlation with the inattention scores on the K-ARS in the right central $(r=0.543$, $p=0.037$ ) region. Fig. 2 presents the scattergrams, which show significant correlations between theta power and inattention scores on the K-ARS in the frontal region.

Furthermore, the theta power in ADHD patients was positively correlated with reaction times in the visual CPT. The analysis revealed that theta power was significantly correlated with the global $(r=0.679, p=0.022)$, left central $(r=0.729, p=0.011)$, and right central $(r=0.729$, $p=0.011$ ) reaction times to the visual CPT regions. Fig. 3 presents the scattergrams, which show significant correlations between theta power and reaction times to the visual CPT in the central region.

The power of the gamma frequency band was sig-

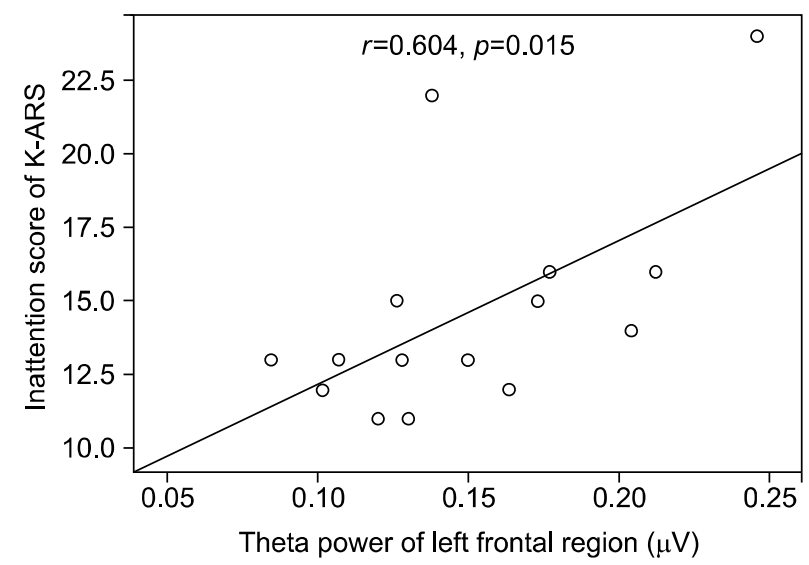

nificantly positively correlated with commission errors on the auditory CPT in the right central region $(r=0.781$, $p=0.005$ ).

We found no significant correlations between qEEG relative power and K-ARS and ADS test scores in HCs.

\section{DISCUSSION}

Our study was designed to examine the relationship between a specific band of qEEG power and various psychometric variables, such as inattention, hyperactivity, and the components of CPTs among ADHD patients. Among patients with ADHD, (1) theta power across the brain was significantly correlated with K-ARS inattention scores; (2) theta power was significantly positively correlated with reaction times on the CPT; (3) gamma-band power was significantly positively correlated with commission errors on the auditory CPT; and (4) theta/alpha and the-

Fig. 2 Correlations between theta power and Korean version of the ADHD Rating Scale (K-ARS) inattention score in the left and right frontal regions. $A D H D$, attention deficit hyperactivity disorder.
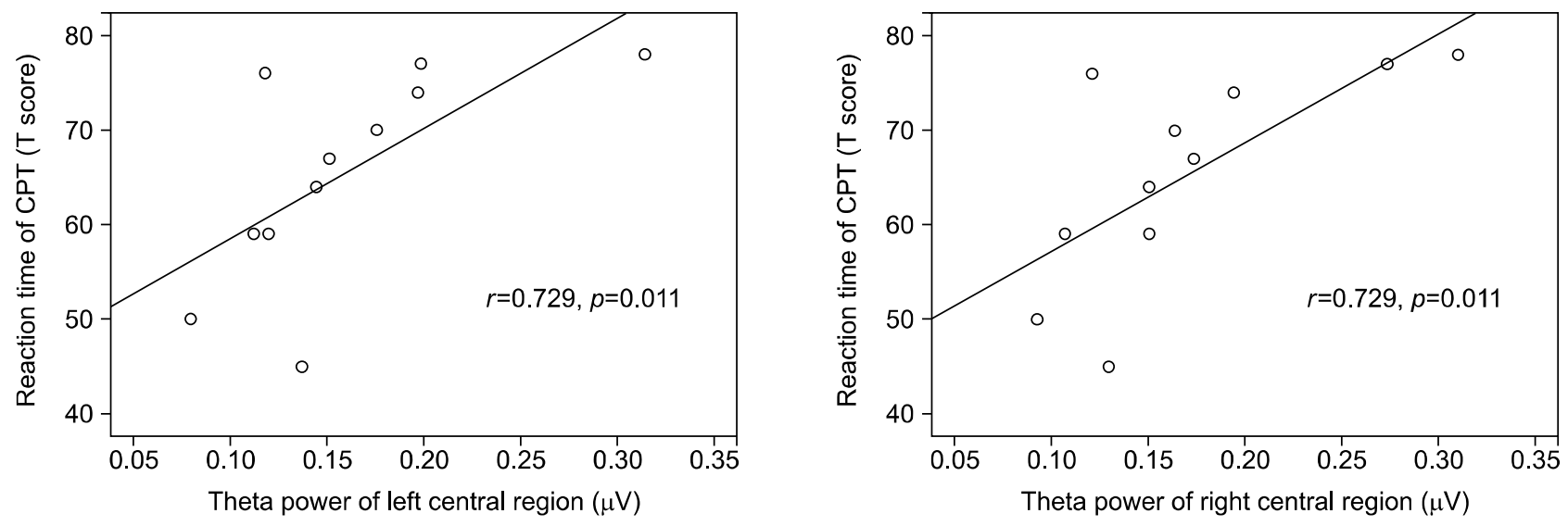

Fig. 3 Correlations between theta power and reaction time of continuous performance test (CPT) in the left and right central regions. 
ta/beta ratios were significantly negatively correlated with both commission and omission errors on the auditory CPT.

Theta power in ADHD patients was significantly positively correlated with inattention scores on the K-ARS, which is standardized in Korea and known for its high validity and reliability. In particular, significant correlations were found in the left and right frontal and the left central regions, and the theta/alpha ratio showed a positive relationship in the right central region. These findings are consistent with the results of previous studies. Clarke et al. ${ }^{20)}$ reported that children with ADHD exhibited increased absolute and relative theta power and reduced relative alpha and beta power compared with children without this disorder. Barry et al. ${ }^{6)}$ concluded that the elevated relative theta power and the reduced relative alpha and beta power were most reliably associated with ADHD. Several other investigators have hypothesized that ADHD involves structural and functional brain abnormalities in the frontal-striatal circuitry. ${ }^{21)}$ Mattes $^{22)}$ found that ADHD is a brain disorder affecting the prefrontal cortex, and Barkley ${ }^{23)}$ emphasized the central role of attention and executive dysfunction in children diagnosed with ADHD. Our results support a previous hypothesis that frontal and central regional brain deficits are major pathological factors in patients with ADHD.

We found a significant positive correlation between theta power and reaction times to visual tasks in ADHD patients. These findings are consistent with those of a previous study of 53 children with ADHD that found that reaction-time variability was an ubiquitous and robust phenomenon in children with ADHD. ${ }^{24)}$ Chee et al. ${ }^{25)}$ examined 51 ADHD patients and confirmed that they had slower reaction times in CPTs than did normal controls. Williams et al. $^{26)}$ also explored the inconsistency in fast and slow reaction times in 72 adolescents and highlighted the importance of fluctuations in cognitive performance in ADHD patients, which affected the fast and slow portions of the reaction-time distribution.

We also found that gamma power was significantly positively correlated with commission errors on the auditory CPT in the right central region of children with ADHD. These results seem to confirm previous reports that auditory gamma-band responses reflect impaired motor inhibition and that one mechanism underpinning the early etiology of ADHD is impaired processing of auditory stimuli. ${ }^{27)}$ Choi et al. ${ }^{28)}$ investigated resting-state EEG activities in subjects with Internet addiction and reported that the study group showed increased gamma-band activity compared with normal controls. In addition, the au- thors found that gamma EEG activities were significantly associated with the severity of Internet addiction as well as with the extent of impulsivity. Lenz et al. ${ }^{29)}$ revealed a strong task-related enhancement in the gamma-band responses in the parieto-occipital areas in ADHD patients. These authors found that the augmentation of gamma power was not associated with cognitive performance, whereas healthy subjects exhibited a strong positive correlation between gamma activity and cognitive performance. They interpreted these findings as evidence of enhanced excitation levels and unspecific activation of processing resources in ADHD patients. Therefore, in contrast to healthy controls, the increased gamma-band power of patients with ADHD or Internet addiction seemed to be related to impulsivity and disinhibition, which caused increased commission errors during auditory CPTs.

In this study, the theta/alpha and theta/beta ratios were significantly negatively correlated with commission and omission errors on the auditory CPT, which seems to contradict our assumption that theta power may reflect the severity of ADHD symptoms. However, it has been suggested that auditory commission and omission errors have a stronger relationship with the intellectual ability of subjects rather than with their ADHD symptoms. Park et al. ${ }^{30)}$ reported that highly intelligent ADHD patients, with IQs of 120 and above, performed better that normally intelligent ADHD patients, with IQs between 70 and 120, with respect to errors of omission and commission on visual-auditory CPTs, even after controlling for age and gender ( $\mathrm{n}=266$, aged 5-15 years). Our study also supports findings of significant negative correlations between IQ and visual omission errors $(r=-0.783, p=0.007)$, and our results suggest a need to standardize the commission and omission variables of CPTs in relation to IQs.

Although our study demonstrated a strong relationship between the EEG results and psychometric scores of patients with ADHD, it also has several limitations. First, we did not stratify our analysis according to ADHD subtype because we studied a relatively small sample. ADHD has three subtypes based on two behavioral dimensions: inattentiveness, hyperactivity/impulsiveness, and both. ${ }^{31)}$ The inattention dimension includes difficulty sustaining attention, distractibility, lack of persistence, and disorganization. The hyperactivity/impulsiveness dimension includes excessive motor activity and impulsive responses. ${ }^{32)}$ Therefore, we could not identify potential differences among the three subtypes of ADHD. Further research is required to elucidate the relationship between EEG results and ADHD subtypes. Second, we could not analyze caus- 
al relationships between EEG data and ADS scores with regard to such parameters as reaction times and errors of omission and commission. Third, because only the ADHD patients performed CPTs, we were not able to study differences between the study and control groups in this regard. Finally, we used $60 \mathrm{~s}$ of EEG data in this study, but data gathered during a longer period of time would produce more reliable results. $^{33)}$

In conclusion, we found a significant positive correlation between theta-band power and the inattention scores on the K-ARS in the frontal and the central regions of patients with ADHD. In addition, theta power was significantly positively correlated with reaction times and commission errors on CPTs. Moreover, increased gamma power was positively correlated with auditory commission errors in the right central region. Our results suggest that the qEEG of the resting EEG may be a useful clinical correlate of ADHD.

\section{Acknowledgments}

This research was supported by a Basic Science Research Program through the National Research Foundation of Korea (NRF) funded by the Ministry of Education, Science and Technology (No. 2012R1A1A2043992).

\section{REFERENCES}

1. Cantwell DP. Attention deficit disorder: a review of the past 10 years. J Am Acad Child Adolesc Psychiatry 1996;35:978987.

2. APA. Diagnostic and statistical manual of mental disorders: DSM-IV. 4th ed. American Psychiatric Association;1994.

3. Kim JY, Ahn DH, Shin YJ. An epidemiological study of attention-deficits hyperactivity disorder and learning disabilities in a rural area. J Korean Neuropsychiatr Assoc 1999;38:784-793.

4. Huang-Pollock CL, Karalunas SL, Tam H, Moore AN. Evaluating vigilance deficits in ADHD: a meta-analysis of CPT performance. J Abnorm Psychol 2012;121:360-371.

5. Douglas VI. Cognitive control processes in attention deficit/ hyperactivity disorder. Handbook of disruptive behavior disorders. New York:Plenum Publishing Company;1999. p.105-138.

6. Barry RJ, Clarke AR, Johnstone SJ. A review of electrophysiology in attention-deficit/hyperactivity disorder: I. Qualitative and quantitative electroencephalography. Clin Neurophysiol 2003;114:171-183.

7. Chabot RJ, Serfontein G. Quantitative electroencephalographic profiles of children with attention deficit disorder. Biol Psychiatry 1996;40:951-963.

8. Mann CA, Lubar JF, Zimmerman AW, Miller CA, Muenchen RA. Quantitative analysis of EEG in boys with attention-deficit-hyperactivity disorder: controlled study with clinical implications. Pediatr Neurol 1992;8:30-36.

9. Monastra VJ, Lubar JF, Linden M, VanDeusen P, Green G, Wing W, et al. Assessing attention deficit hyperactivity disorder via quantitative electroencephalography: an initial validation study. Neuropsychology 1999;13:424-433.

10. El-Sayed E, Larsson JO, Persson HE, Rydelius PA. Altered cortical activity in children with attention-deficit/hyperactivity disorder during attentional load task. J Am Acad Child Adolesc Psychiatry 2002;41:811-819.

11. Song DH, Shin DW, Jon DI, Ha EH. Effects of methylphenidate on quantitative EEG of boys with attention-deficit hyperactivity disorder in continuous performance test. Yonsei Med J 2005;46:34-41.

12. Schachar R, Rutter M, Smith A. The characteristics of situationally and pervasively hyperactive children: implications for syndrome definition. J Child Psychol Psychiatry 1981;22:375-392.

13. Park K, Yoon J, Park H, Park H, Kwon K. Korean educational developmental institute-Wechsler intelligence scale for children (KEDI-WISC). Seoul:Korean Educational Development Institute;2002.

14. So YK, Noh JS, Kim YS, Ko SG, Koh YJ. The reliability and validity of korean parent and teacher adhd rating scale. J Korean Neuropsychiatr Assoc 2002;41:283-289.

15. Greenberg LM, Waldman ID. Developmental normative data on the test of variables of attention (T.O.V.A.). J Child Psychol Psychiatry 1993;34:1019-1030.

16. Shin M, Cho S, Chun S, Hong K. A study of the development and standardization of ADHD diagnostic system. J Korea Acad Child Adolesc Psychiatry 2000;11:91-99.

17. Zion-Golumbic E, Golan T, Anaki D, Bentin S. Human face preference in gamma-frequency EEG activity. Neuroimage 2008;39:1980-1987.

18. Gianotti LR, Künig G, Lehmann D, Faber PL, PascualMarqui RD, Kochi K, et al. Correlation between disease severity and brain electric LORETA tomography in Alzheimer's disease. Clin Neurophysiol 2007;118:186-196.

19. Jung HT, Lee SH, Kim JN, Lee KJ, Chung YC. Quantitative electroencephalography and low resolution electromagnetic tomography imaging of Alzheimer's disease. Psychiatry Investig 2007;4:31-37.

20. Clarke AR, Barry RJ, McCarthy R, Selikowitz M. Age and sex effects in the EEG: differences in two subtypes of attention-deficit/hyperactivity disorder. Clin Neurophysiol 2001;112:815-826.

21. Seidman LJ, Valera EM, Makris N. Structural brain imaging of attention-deficit/hyperactivity disorder. Biol Psychiatry 2005; 57:1263-1272.

22. Mattes JA. The role of frontal lobe dysfunction in childhood hyperkinesis. Compr Psychiatry 1980;21:358-369.

23. Barkley RA. Behavioral inhibition, sustained attention, and executive functions: constructing a unifying theory of ADHD. Psychol Bull 1997;121:65-94.

24. Epstein JN, Langberg JM, Rosen PJ, Graham A, Narad ME, Antonini $\mathrm{TN}$, et al. Evidence for higher reaction time variability for children with ADHD on a range of cognitive tasks including reward and event rate manipulations. Neuropsychology 2011;25:427-441.

25. Chee P, Logan G, Schachar R, Lindsay P, Wachsmuth R. Effects of event rate and display time on sustained attention in hyperactive, normal, and control children. J Abnorm Child Psychol 1989;17:371-391.

26. Williams BR, Strauss EH, Hultsch DF, Hunter MA, Tannock R. Reaction time performance in adolescents with attention deficit/hyperactivity disorder: evidence of inconsistency in the fast and slow portions of the RT distribution. $J$ Clin Exp Neuropsychol 2007;29:277-289.

27. Yordanova J, Banaschewski T, Kolev V, Woerner W, Rothenberger A. Abnormal early stages of task stimulus 
processing in children with attention-deficit hyperactivity disorder-evidence from event-related gamma oscillations. Clin Neurophysiol 2001;112:1096-1108.

28. Choi JS, Park SM, Lee J, Hwang JY, Jung HY, Choi SW, et al. Resting-state beta and gamma activity in Internet addiction. Int $J$ Psychophysiol 2013;89:328-333.

29. Lenz D, Krauel K, Schadow J, Baving L, Duzel E, Herrmann CS. Enhanced gamma-band activity in ADHD patients lacks correlation with memory performance found in healthy children. Brain Res 2008;1235:117-132.

30. Park MH, Kweon YS, Lee SJ, Park EJ, Lee C, Lee CU. Differences in performance of ADHD children on a visual and auditory continuous performance test according to $I Q$.
Psychiatry Investig 2011;8:227-233.

31. Sagvolden T, Johansen EB, Aase H, Russell VA. A dynamic developmental theory of attention-deficit/hyperactivity disorder (ADHD) predominantly hyperactive/impulsive and combined subtypes. Behav Brain Sci 2005;28:397-419.

32. Lahey BB, Pelham WE, Stein MA, Loney J, Trapani C, Nugent $\mathrm{K}$, et al. Validity of DSM-IV attention-deficit/ hyperactivity disorder for younger children. J Am Acad Child Adolesc Psychiatry 1998;37:695-702.

33. Maltez J, Hyllienmark L, Nikulin VV, Brismar T. Time course and variability of power in different frequency bands of EEG during resting conditions. Neurophysiol Clin 2004;34:195-202. 